\title{
ERRATUM
}

\author{
G. Bernardi · G. Bucciarelli · D. Costagliola \\ D. R. Robertson · J. B. Heiser
}

\section{Evolution of coral reef fish Thalassoma spp. (Labridae). 1. Molecular phylogeny and biogeography}

\section{Marine Biology (2003): DOI 10.1007/s00227-003-1199-0}

The "Notes added in proof" at the end of the paper contain several errors and a sentence that is incomprehensible. The "Notes added in proof" should read:

Notes added in proof While this manuscript was in press, two studies came to our attention: 1. A phylogeny of the closely related genus Halichoeres was done by P. Barber and D. Bellwood. This study determined that the Caribbean species Halichoeres maculipinna was more closely related to Thalassoma spp. than to other Halichoeres species. When including $H$. maculipinna in our dataset, we found that it is close to Thalassoma but not within the genus. It is, however, an ideal outgroup to be used. When $H$. maculipinna was used as an outgroup, our results were unchanged (we would like to acknowledge P. Barber and D. Bellwood for permission to use their data before publication). 2. A new species of Thalassoma has recently been described [Randall JE (2003) Thalassoma nigrofasciatum, a new species of labrid fish from the south-west Pacific. Aqua 7(1): 1-8]. This species is closely related to T. jansenii and is found in the Great Barrier Reef and adjacent areas. As such, our $T$. jansenii sample should be labeled $T$. nigrofasciatum. We sequenced the 12S rRNA, 16S rRNA and the cytochrome $b$ regions for 2 individuals of bona fide T. jansenii (collected in June 1998 by DRR in Ishigaki, Japan). The two individuals had identical sequences. Their $16 \mathrm{~S}$ sequence was identical to the Australian T. nigrofasciatum and differed by one nucleotide at the cytochrome $b$ locus. We conclude that $T$. nigrofasciatum and $T$. jansenii are either very closely related species with no detectable genetic divergence at these two loci, or that $T$. nigrofasciatum is a color variant of $T$. jansenii.
The online version of the original article can be found at http:// dx.doi.org/10.1007/s00227-003-1199-0

G. Bernardi $(\varangle) \cdot$ G. Bucciarelli $\cdot$ D. Costagliola

Department of Ecology and Evolutionary Biology,

University of California,

100 Shaffer Road,

Santa Cruz, CA 95060, USA

E-mail: bernardi@biology.ucsc.edu

Fax: + 1-831-4594882

D. Costagliola

Dipartimento di Scienze della Vita,

Seconda Università di Napoli,

Via Vivaldi 43, 81100 Caserta, Italy

D. R. Robertson

Smithsonian Tropical Research Institute,

Apartado 2072, Balboa, Rep. de Panama

J. B. Heiser

Shoals Marine Laboratory and Department of Ecology

and Evolutionary Biology,

Cornell University, Ithaca,

NY 14853, USA

Present address: G. Bucciarelli Stazione Zoologica A. Dohrn, Naples, Italy 